\title{
Death Anxiety and Depression among Long and Short Route Truck Drivers
}

\author{
L.N. Bunker ${ }^{1}$, Vishnu Narayan ${ }^{2 *}$
}

\section{ABSTRACT}

The present study aims to study depression and death anxiety among long route and short route truck drivers. The sample size $(n=60)$ truck drivers 30 short-route drivers and 30 long route drivers were selected using random sampling technique. The data was collected using Thakur Death- Anxiety Scale and Beck Depression Inventory. Results shows that significant difference exist on measures of depression and death anxiety scales among long and short route truck drivers. Significant difference was found among death anxiety and depression of short route drivers and long route drivers and all truck drivers. High Pearson correlation was found among death anxiety and depression among truck drivers.

Keywords: Truck driver, Depression, Death Anxiety.

Death anxiety is an abnormal fear of dying. Fear of death is an emotional reaction involving subjective feelings of unpleasantness and concern based on contemplation or anticipation of any of the several facts related to death (Feifel, 1995).

Truck drivers has to work for irregular working hours, alone, away from home, in varied climatic conditions with fear accidents on road. He continuously works alone away from family, friends and peers under such pressure for a long duration, he suffers from fear that if some day he may not reach home alive. This fear of uncertainty leads to anxiety related to death which is common in truck drivers. Thus trucking is categorized as one of the highest-risk occupations. Long route truck drivers face many occupational stressors including constant time pressures, social isolation, disrespectful treatment from others, driving hazards such as weather changes, traffic, and road conditions, and violence or fear of violence which leads to death anxiety (Shattell, et. al., 2010).

Depression is a major public health problem. It tends to have a chronic course, produces disability and is associated with suicide (Chisholm, Sanderson, et al, 2004; Insel \& Charney, 2003). Truck drivers are at increased risk for depression when compared to the general population (Da Silva et. al., 2009). Shen, Li et al, (2013) investigated depression status and

\footnotetext{
${ }_{1}^{1}$ Associate Professor, Department of Psychology, Jai Narain Vyas University, Jodhpur, India

${ }^{2}$ Ph.D Scholar, Department of Psychology, Jai Narain Vyas University, Jodhpur, India *Corresponding Author

(C) 2015 I L Bunker, V Narayan; licensee IJIP. This is an Open Access Research distributed under the terms of the Creative Commons Attribution License (http://creativecommons.org/licenses/by/2.0), which permits unrestricted use, distribution, and reproduction in any Medium, provided the original work is properly cited.
} 
associated factors in occupational truck drivers. It was reported that depression is present in professional drivers, especially those with $<1$ year of driving experience. The level of depression is associated with driving experience, education status and personality (Shen, Li et al, 2013).

Wong, Tam, \& Leung (2007) in a study on the sample of 1,200 truck drivers in China found that longer and more frequent road trips were linked with increases in depressive symptoms. Truckers regularly experience high levels of occupational stress (Apostolopoulos \& S"onmez,; Essenberg, 2003; Saltzman \& Belzer, 2003) that places them at risk for social, psychological, and psychiatric problems such as depression (Da Silva et al., 2009).

\section{RATIONALE OF THE STUDY:}

Transport system and truckers are the backbone of the nation. Their mental and physical health is also important aspect for the growth of a nation In India very few studies are conducted related to the mental health issues of truck drivers. As a result the present study was designed to study the mental health related issues among this population.

It is expected that the findings of present study will assist the mental health worker working in area to understand and treat the mental health issues among truck driver population.

\section{OBJECTIVES}

1. To study the death anxiety among short route truck drivers and long route truck drivers.

2. To study the depression among short route truck drivers and long route truck drivers.

3. To study the death anxiety and depression among long route truck drivers.

4. To study the death anxiety and depression among short route trucking.

5. To study the death anxiety and depression among truck drivers.

6. To study the correlation between death anxiety and depression among truck drivers.

\section{Hypothesis}

1. There will be significant difference in the measures of death anxiety among short route truck drivers and long route truck drivers.

2. There will be significant difference in the measures of depression among short route truck drivers and long route truck drivers.

3. There will be no significant difference between the measures of death anxiety and depression among truck drivers.

\section{METHOD}

\section{Variables}

- Independent variables: Long route truck drivers and Short route truck drivers

- Dependent Variables: Depression and Death Anxiety. 


\section{Sample}

Random sampling technique was used. 60 truck drivers were selected among which 30 were short route truck drivers and 30 were long route truck drivers.

\section{Measures}

- Thakur death Anxiety Scale by Giridharprasad Thakur and Manju Thakur (1985) was used. The scale consist a 16 items: 11 were positively worded and 5 were negatively worded. The positive worded items were to be rated 5 point scale. The test retest reliability of the test is 0.86 and validity 0.75 .

- Beck Depression Inventory II by Aaron T. Beck (1996) was used. This self-report inventory scale consists 21- multiple-choice question. The test retest reliability of the test is 0.93 and the construct validity of BDI-II is 0.93 .

\section{Statistical Analysis}

Differences among the means of research variables studied using t-test.

Pearson product movement correlation was used to find the relationship between depression and death anxiety of truck drivers. All analysis was conducted using SPSS version 20.

\section{RESULTS}

Result table 1: Death Anxiety among long route truck drivers and short route truck drivers.

\begin{tabular}{|l|l|l|l|l|l|}
\hline Category & N & Mean & SD & t & p \\
\hline Long route truck drivers & 30 & 62.33 & 2.59 & 9.43 & 0.01 \\
\hline Short route truck drivers & 30 & 54.73 & 3.57 & & \\
\hline
\end{tabular}

Table 1 illustrates the means and SD of long and short route truck drivers on Thakur Death Anxiety Scale. Mean and SD of long route truck drivers was found to be 62.33 and 2.59 and of short route truck drivers was found to be 54.73 and 3.57 and t result indicates that there is significant difference between long route truck drivers and short route truck drivers on death anxiety scale, as $\mathrm{t}=9.43$.

Result table 2: Depression among long route truck drivers and short route truck drivers.

\begin{tabular}{|l|l|l|l|l|l|}
\hline Category & N & Mean & SD & t & p \\
\hline Long route truck drivers & 30 & 34.20 & 3.02 & 9.01 & 0.01 \\
\cline { 1 - 3 } Short route truck drivers & 30 & 25.53 & 4.31 & & \\
\cline { 1 - 3 }
\end{tabular}

Table 2 illustrates the means and SD's of the long and short route truck drivers on Beck Depression Inventory. Mean and SD of long route truck drivers was found to be 34.20 and 3.02 and of short route truck drivers was found to be 25.53 and 4.31 and t result indicates that there is significant difference between long route truck drivers and short route truck drivers on death anxiety scale, as $t=9.01$. 
Result table 3: Death anxiety and depression among long route truck drivers.

\begin{tabular}{|l|l|l|l|l|l|}
\hline Category & N & Mean & SD & t & p \\
\cline { 1 - 4 } Death anxiety & 30 & 62.33 & 2.59 & 38.71 & 0.01 \\
\cline { 1 - 4 } Depression & 30 & 34.20 & 3.02 & & \\
\hline
\end{tabular}

Table 3 illustrates the means and SD's of the long route truck drivers on Thakur Death Anxiety Scale and Beck Depression Inventory. Mean and SD on Death Anxiety Scale was found to be 62.33 and 2.59 and on Beck Depression Scale was found to be 34.20 and 3.02 and t result indicates that there is significant difference between the measures of death anxiety and depression of long route truck drivers, as $\mathrm{t}=38.71$.

Result table 4: Death anxiety and depression among short route truck drivers.

\begin{tabular}{|l|l|l|l|l|l|}
\hline Category & N & Mean & SD & t & p \\
\hline Death anxiety & 30 & 54.73 & 3.57 & 28.56 & 0.01 \\
\cline { 1 - 4 } Depression & 30 & 25.53 & 4.31 & & \\
\hline
\end{tabular}

Table 4 illustrates the means and SD's of the short route truck drivers on Thakur Death Anxiety Scale and Beck Depression Inventory. Mean and SD on Death Anxiety Scale was found to be 54.73 and 3.57 and on Beck Depression Scale was found to be 25.53 and 4.31 and t result indicates that there is significant difference between the measures of death anxiety and depression of short route truck drivers, as $t=28.56$.

Result Table 5: Death anxiety and depression among truck drivers.

\begin{tabular}{|l|l|l|l|l|l|}
\hline Category & N & Mean & SD & t & p \\
\cline { 1 - 4 } Death anxiety & 60 & 58.53 & 4.92 & 29.42 & 0.01 \\
\cline { 1 - 3 } Depression & 60 & 29.86 & 5.72 & & \\
\hline
\end{tabular}

Table 5 illustrates the means and SD's of all truck drivers on Thakur Death Anxiety Scale and Beck Depression Inventory. Mean and SD on Death Anxiety Scale was found to be 58.53 and 4.92 and on Beck Depression Scale was found to be 29.86 and 5.72 and t result indicates that there is significant difference between the measures of death anxiety and depression of all truck drivers, as $\mathrm{t}=29.42$.

Result table 6: Correlation among death anxiety and depression of truckers.

\begin{tabular}{|l|l|l|l|}
\hline Category & N & Correlation & $\boldsymbol{p}$ \\
\hline Death Anxiety & 60 & 0.77 & 0.01 \\
\cline { 1 - 2 } Depression & 60 & & \\
\hline
\end{tabular}

Table 6 Illustrates the correlation between death anxiety and depression among all truck drivers and it is reported that correlation is highly significant at 0.01 level, as $r=0.77$.

\section{DISCUSSION}

Trucking is a very risky profession. A person works for irregular working hours, alone away from their family friends and peer under a great pressure of reaching the destination at time. The 
present study attempts to investigate the death anxiety and depression among long and short route truck drivers.

The first objective of the study is to compare death anxiety among long route truck drivers and short route truck drivers. Results shows that there exists significant difference between the long route and the short route truck drivers. The obtained mean and t- value shows that the long route truck drivers has more death anxiety as compared to short route truck drivers. The findings are similar to findings of Shattell et. al. (2010) which suggests that long route truck drivers face more fear or fear of violence. This leads to high death anxiety among long route truck drivers.

The second objective of the present study is to compare the depression among long route truck drivers and short route truck drivers. Results shows that there exists significant difference between the long route and the short route truck drivers. The obtained mean and t value shows that long route truck drivers face more depression as compared to short route truck drivers. In a study Morrow \& Crum (2004) found that long haul truck drivers are frequently subjected to work overload, high mileage exposure, and irregular work/rest schedule and have little pace over their work. They are commonly isolated at work and may be exposed to daily hassles in driving. Therefore, long haul truck drivers should be regarded as a potentially vulnerable population towards depression anxiety and other mental disorders.

The third fourth and fifth objective of the study is to compare the level of death anxiety and depression among long, short route and over all truck drivers. Results show significance difference between the death anxiety and depression among long, short route and over all truck drivers. In a study Enrique (1995) suggests that death anxiety was predicted by depression.

The sixth objective of the present study is to find the correlation between death anxiety and depression among truck drivers. Results shows that there exist a is highly significant correlation. The finding are similar to Almostadi (2012) which suggests significant correlation between death anxiety and depression and Enrique (1995) which suggests that depression was positively correlated with death anxiety.

\section{CONCLUSION}

Long route truck drivers are found to be high on death anxiety and depression in comparison to short route truck drivers. It was also found that long and short and over all truck drivers are high on death anxiety as compared to depression. High correlation is also present between death anxiety and depression among truck drivers. Further research is needed to study the mental health issues and to plan effective intervention among truck drivers. 


\section{REFERENCE}

Almostadi, Doaa A., (2012). "The Relationship between Death Depression and Death Anxiety among Cancer Patients in Saudi Arabia”. Graduate Theses and Dissertations. http://scholarcommons.usf.edu/etd/3947

Chisholm D, Sanderson K, Ayuso-Mateos JL, Saxena S (2004). Reducing the global burden of depression: population-level analysis of intervention cost-effectiveness in 14 world regions. Br J Psychiatry 184:393-403.

Da Silva-Júnior FP, De Pinho RSN, De Mello MT, De Bruin VMS, De Bruin PFC, (2009). Risk factors for depression in truck drivers. Social psychiatry and psychiatric epidemiology 44: 125-129. DOI: 10.1007/s00127-008-0412-3

Enrique Gular, (1995). "Depression, death anxiety, and hope among female caregivers of children with HIV/AIDS". ETD Collection for Fordham University. Paper AAI9530029.

Feifel H. (1995). Attitude of the mentally ill towards death. J Nerv Ment Dis; 122: 375 - 380.

Insel TR, Charney DS (2003). Research on major depression: strategies and priorities. JAMA 289:3167-3168.

Morrow PC, Crum MR, (2004). Antecedents of fatigue, close calls, and crashes among commercial motor-vehicle drivers. JSafety Res 35:59-69.

Shattell Mona, Apostolopoulos Yorghos, Sönmez Sevil, Griffin Mary, (2010). Occupational Stressors and the Mental Health of Truckers. Issues in Mental Health Nursing. 2010; 31(9):561-568.DOI:10.3109/01612840.2010.488783.

Shen S1, Li Y, Zhou M, Zhang C, Jiang Y, Kang Y., 2013. Depression status and associated factors in Chinese occupational truck drivers. Cell Biochem Biophys. 2013; 67(3):1497500. DOI: 10.1007/s12013-013-9651-3.

Wong, W. C. W., Tam, S. M., \& Leung, P. W. S. (2007). Cross-border truck drivers in Hong Kong: Their psychological health, sexual dysfunctions and sexual risk behaviors. Journal of Travel Medicine, 14, 20-30.

Webs

http://fordham.bepress.com/dissertations/AAI9530029 